\title{
CIDADE EM DISPUTA: NARRATIVAS DO PASSO DOS NEGROS EM PELOTAS, RS
}

\author{
Melina Monks da Silveira ${ }^{1}$ \\ Louise Prado Alfonso ${ }^{2}$ \\ Larissa Osterberg da Cruz ${ }^{3}$
}

O ensaio apresentado se desenvolveu no âmbito do projeto pesquisa "Margens: grupos em processos de exclusão e suas formas de habitar Pelotas" e do projeto de extensão "Narrativas do Passo dos Negros: um exercício de etnografia coletiva para antropólogos e antropólogas em formação", ambos desenvolvidos pelo Grupo de Estudos Etnográficos Urbanos - GEEUR da Universidade Federal de Pelotas - UFPEL.

O Passo dos Negros é uma comunidade periférica localizada em Pelotas, às margens do canal São Gonçalo. Trata-se de um local de grande importância para a cidade, pois foi o primeiro aldeamento da região, onde localizava-se o primeiro porto da cidade de Pelotas, um importante ponto para a travessia de gado (Caminho das Tropas) e também comercialização de pessoas escravizadas. Em outro momento ali esteve um dos maiores engenhos de arroz da América do Sul. A localidade representa um lugar de luta e resistência negra ao longo do tempo. Hoje essa área está passando por um processo de especulação imobiliária e a comunidade corre risco de ser removida do local.

Tanto no primeiro, quanto no segundo Plano Diretor da cidade de Pelotas, a região do Passo dos Negros foi ocultada nos mapas e nas diretrizes de legislação urbana, sendo considerada zona rural. Já na revisão do III Plano Diretor de 2018, a área consta como vazio urbano, mesmo com habitações já consolidadas. Hoje a de valorização imobiliária tomou lugar de protagonista na produção e ocupação oficial do espaço, abarcando o centro jurídico da cidade, Shopping, Bairro planejado com eventos culturais e condomínios fechados, que estão transformando o espaço em uma nova centralidade na cidade. Essas intervenções têm como características intervenções com forte apelo visual, adequando a nova paisagem às demandas de valorização imobiliária, de segurança, ordenamento e limpeza urbana voltadas ao uso ou à reapropriação por

\footnotetext{
${ }^{1}$ Universidade Federal de Pelotas, Brasil. Email: melimonks@gmail.com. ORCID id: https://orcid.org/0000-0003-4449-878X

${ }^{2}$ Universidade Federal de Pelotas, Brasil. Email: louiseturismo@yahoo.com.br ORCID id: https://orcid.org/0000-0001-8602-326X

${ }^{3}$ Universidade Federal de Pelotas, Brasil. Email: larissa.cruzosterberg@hotmail.com ORCID id: https://orcid.org/0000-0003-2002-0730
} 
parte das classes médias e altas que resultam em espaços segregadores e que o fragmentam em diferentes lugares (Leite, 2010).

A paisagem às margens do Canal São Gonçalo tem sofrido alterações significativas nos últimos anos devido às escolhas da gestão municipal de ocupação do solo da cidade, em prol dos interesses dos grandes empreendimentos imobiliários. Impactos esses sociais, ambientais e culturais. Essas alterações nas diretrizes de ocupação do solo mostram a fragilidade da área frente às condições legais oferecidas pelo poder oficial, relacionadas tanto à patrimonialização do espaço quanto às questões ambientais.

As diferentes ações do poder público local relacionadas às políticas públicas de moradia, infraestrutura e preservação do patrimônio existente no Passo dos Negros revelam sua invisibilidade ao longo do tempo, que não insere a comunidade existente no local nas políticas públicas da gestão municipal. Os/as moradores/as lutam por seu direito adquirido de moradia e resistem em permanecer habitando o local, buscando assim, também preservar o patrimônio cultural existente. Nas narrativas e na paisagem percebemos um Passo dos Negros que resiste a longo tempo à invisibilidade, lugar em que há sujeitos que constroem "sua cidade", que fixam suas casas e espaços de pertencimento. A proposta é pensar a cidade fora de pretensões normativas, numa concepção da ideia de uma construção/desconstrução da cidade. O que faz e desfaz a cidade permanentemente? Quais processos e políticas impulsionam o movimento necessário à sua existência, às suas reproduções e transformações? (Agier, 2015). Transformações que fazem a cidade dinâmica, em movimento e com uma relação dialética entre as margens e a centralidade.

\section{REFERÊNCIAS}

AGIER, Michel. Do direito à cidade ao fazer-cidade: o Antropólogo, a margem e o centro. Revista Mana. Rio de Janeiro. vol.21 no.3 Dec. p. 483-498, 2015.

LEITE, Rogério P. A Exaustão das cidades: antienobrecimento e intervenções urbanas em cidades portuguesas e brasileiras. Revista Brasileira de Ciências Sociais, Associação Nacional de Pós-Graduação e Pesquisa em Ciências Sociais. São Paulo, Brasil, v.25 n.72, p. 73 - 88, fevereiro, 2010.

Recebido: 31/05/2020

Aprovado: $08 / 12 / 2020$ 

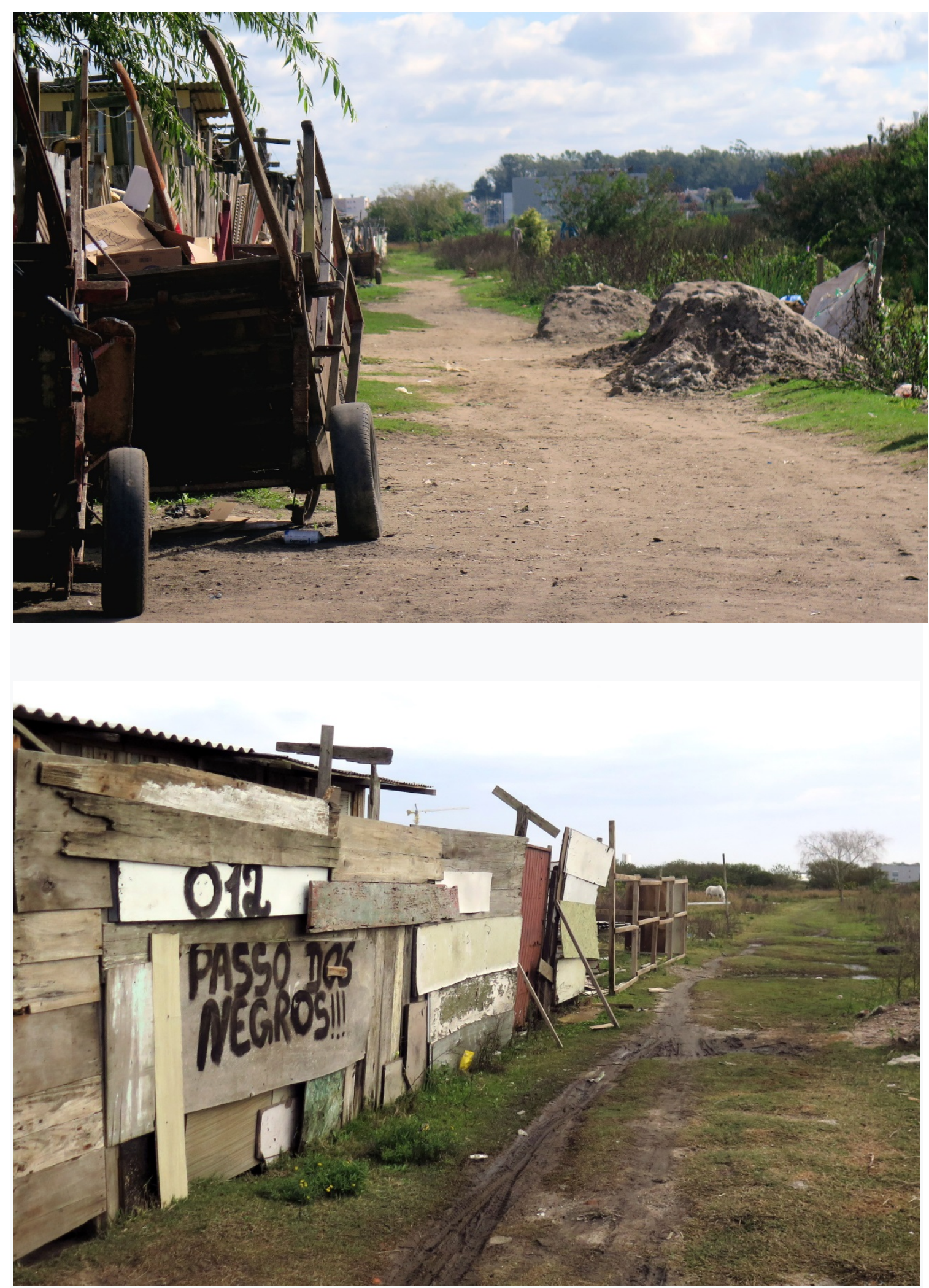

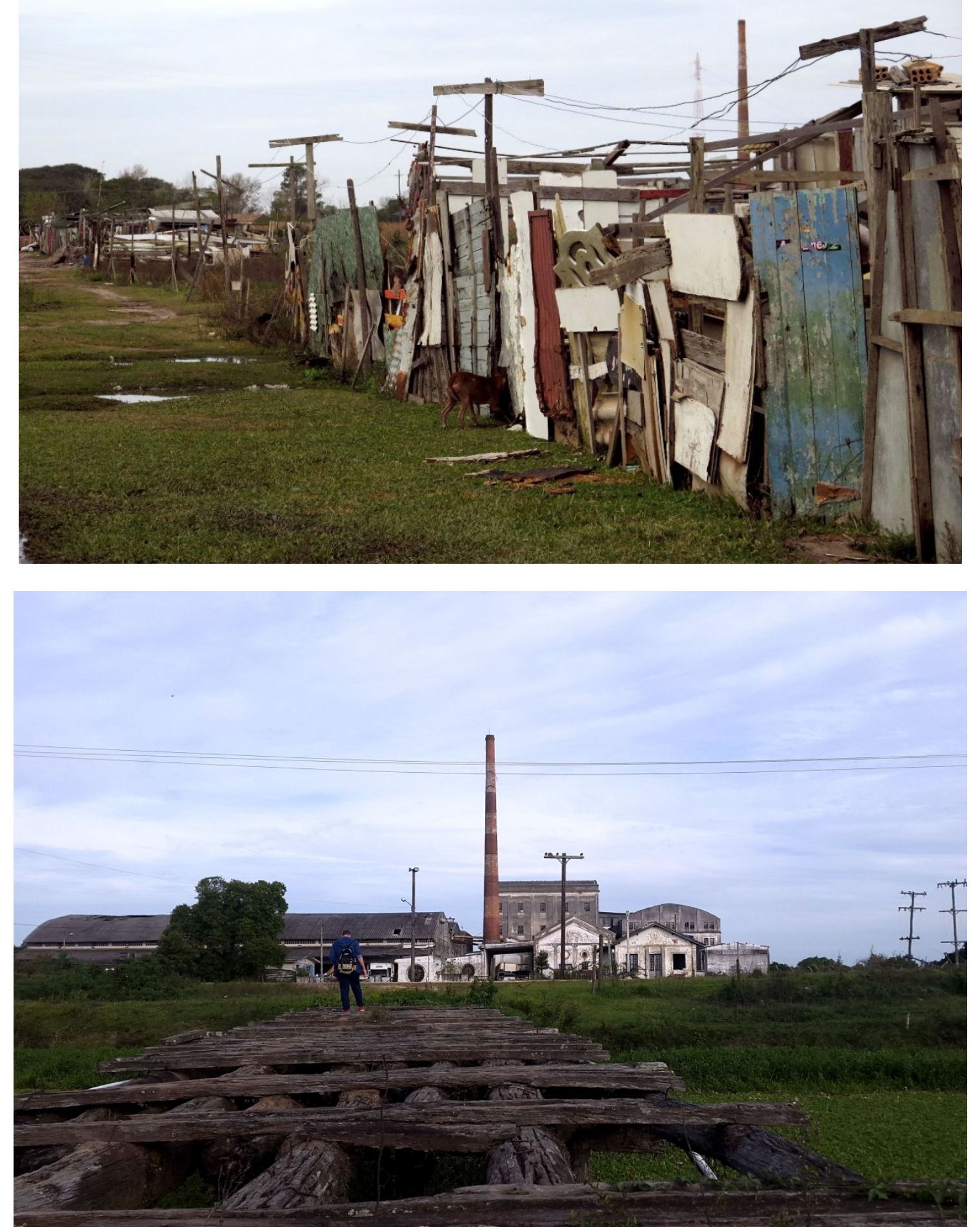

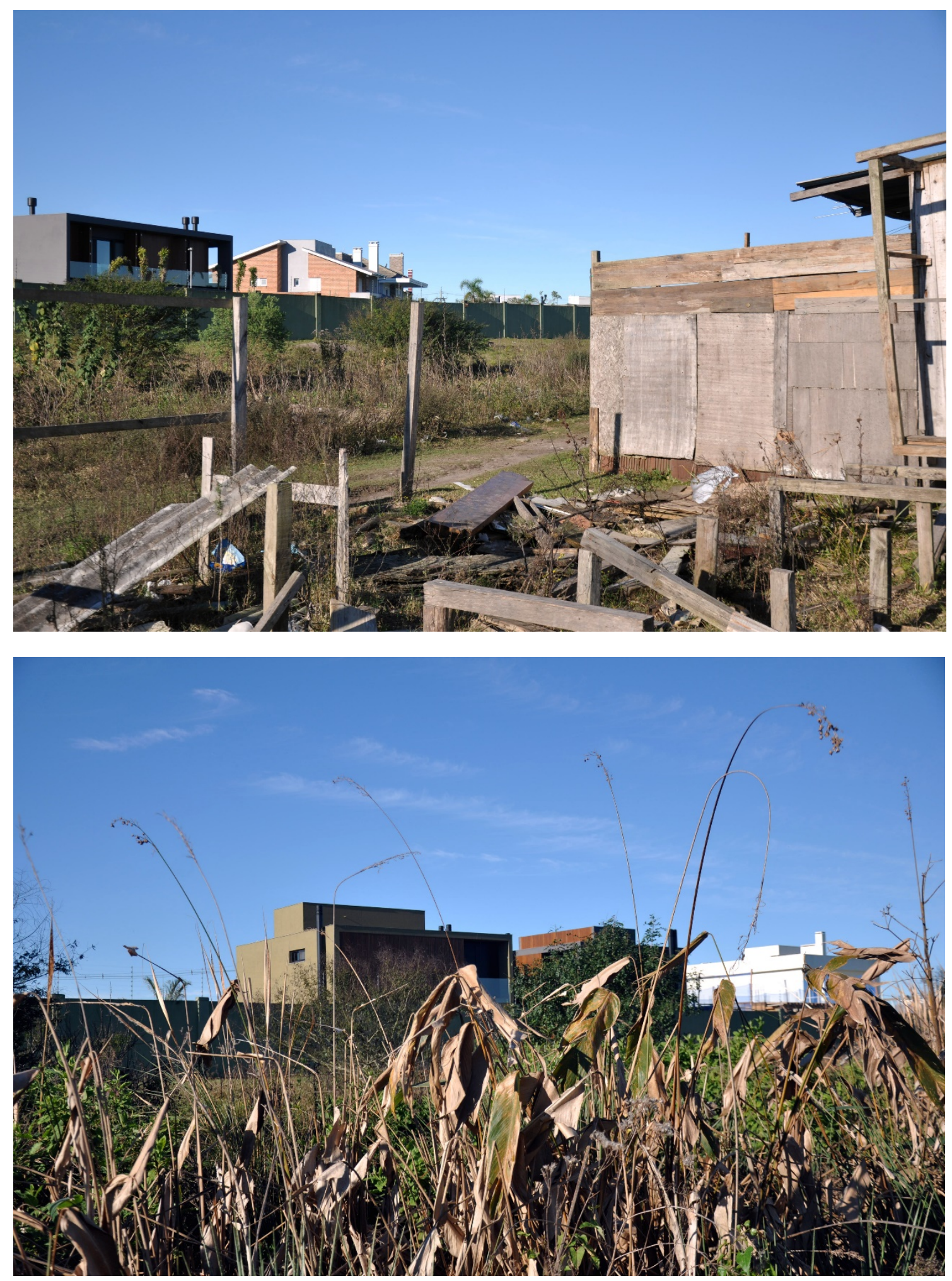

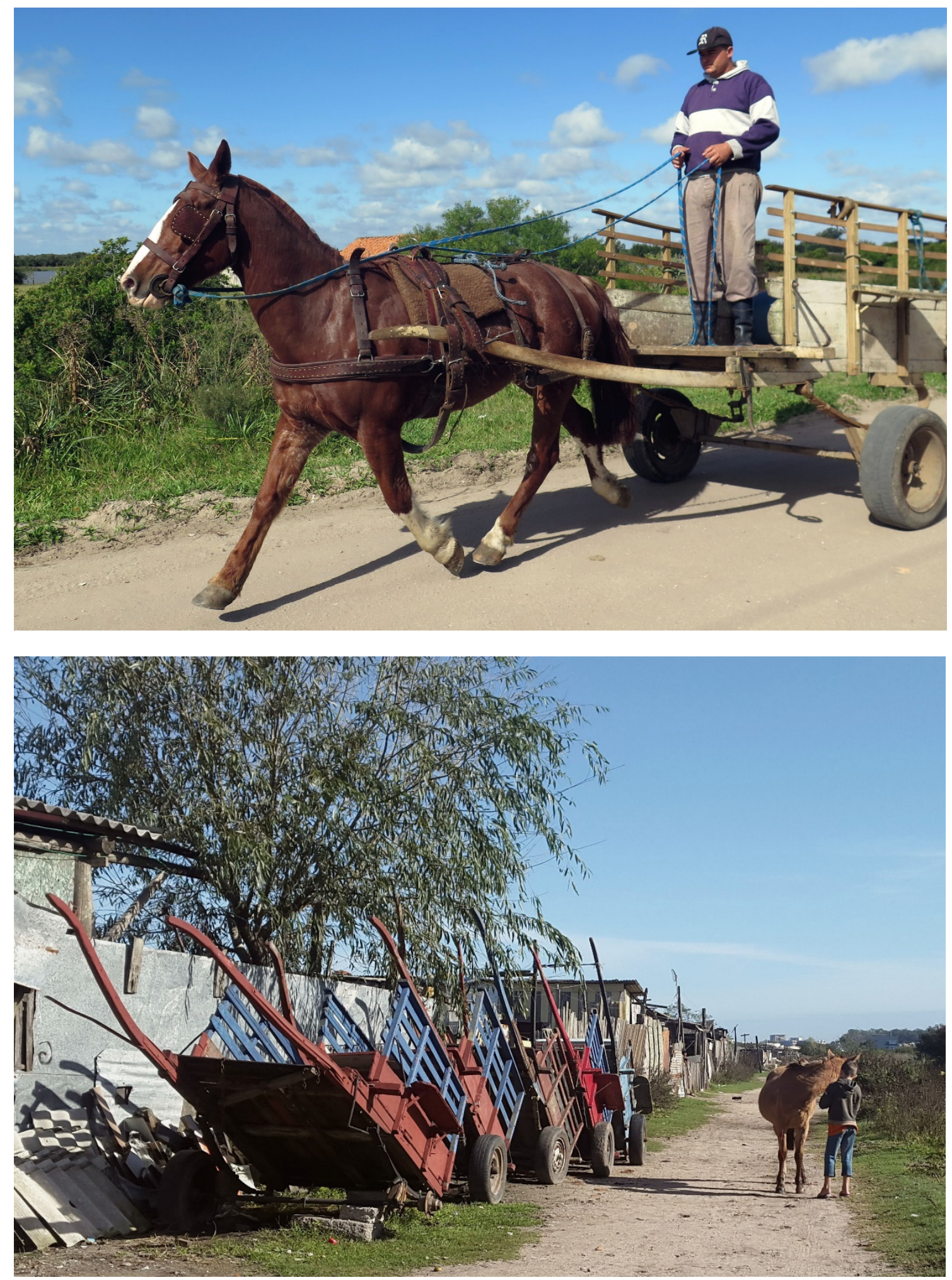